\title{
The Effect of Working Memory Training on Working Memory Capacity and Performance of Novice Karateka

\author{
Behnam Maleki ${ }^{1}$, Mohammad Vaez Mousavi ${ }^{*}$, Abdolah Ghasemi ${ }^{1}$
}

1. Department of Physical Education and Sport Sciences, Faculty of Humanities and Social Sciences, Science and Research Branch, Islamic Azad University, Tehran, Iran 2. Department of Physical Education and Sport Sciences, Faculty of Social Sciences, Imam Hossein University, Tehran, Iran.

Citation: Maleki, B., Vaez Mousavi, M. K., \& Ghasemi, A. (2016). The effect of working memory training on working memory capacity and performance of novice karateka. Journal of Practice in Clinical Psychology, 4(2), 113-120. http://dx.doi.org/10.15412/J.JPCP.06040206

: http://dx.doi.org/10.15412/J.JPCP.06040206

\section{Article info:}

Received: 18 Oct. 2015

Accepted: 10 Feb. 2016

Keywords:

Working memory,

Performance, Traning, Athletes

\section{ABSTRACT}

Objective: This study aimed to investigate the effect of working memory (WM) training on WM capacity and performance of novice karate practitioners (karateka).

Methods: Research method is quasi-experimental with a pretest posttest control group design. A total of 24 karate practitioners were selected among Alborz (Alborz Province, iran) novice karateka by convenience sampling method and were randomly assigned into control and experimental groups. They were asked to complete WM capacity test and performance test. Then, the experimental group underwent a 25 session WM training course. Finally, both group completed the tests again. Instruments of gathering data included digit and spatial WM test, performance test, and WM training software. We used 1-way analysis of covariance (ANCOVA) for data analysis.

Results: Our findings showed that WM training resulted in increase in WM capacity ( $F=61.87$, $\mathrm{P} \leq 0.01)$ and performance $(\mathrm{F}=15.5, \mathrm{P} \leq 0.01)$ of the intervention group.

Conclusion: We suggest that coaches ask athletes to use WM training as a complement to physical exercises.

\section{Introduction}

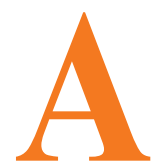

ccording to the Baddeley and Hitch multicomponent model of working memory (1974), which consists of 2 storing subsystems (phonological loop and visuospatial sketchpad) and 1 coordinating system named central executive, working memory (WM) capacity is the amount of information maintained in working memory and preserved from interference (Baddeley
\& Hitch, 1974; Kane, Bleckley, Conway, \& Engle 2001; Engle, 2002; Barrett, Tugade, \& Engle, 2004).

Controlled attention theory of WM (Engle, 2002; Kane \& Engle, 2003) also expresses that WM capacity is the ability of controlling attention for keeping information in an active state and quick restoring capability. Apparently, sportspeople might benefit a greater WM capacity in their sports (Furley \& Memmert, 2010). Controlled processing arises from the central executive aspect of WM and occurs when one focuses on a goal-directed or

\section{* Corresponding Author:}

Mohammad Vaez Mousavi, PhD

Address: Department of Physical Education and Sport Sciences, Faculty of Social Sciences, Imam Hossein University, Tehran, Iran.

Tel: +98 (21) 44205819

E-mail:vaez_mohammad@yahoo.com.au 
endogenous fashion (Barrett, Tugade, \& Engle, 2004). So goal-oriented behavior needs active storing of relevant information and controlling irrelevant information for performing the task. Generally, to be adaptive in this complex world, one must filter out irrelevant information and selectively focuses on more important aspects of the environment (Abdi, Chalabianloo, \& Jabari, 2016).

The nature of sporting situations clearly shows the importance of psychological skills such as WM capacity. In general, people make accurate decisions based on relevant information and regardless of irrelevant information to the situations (Furley \& Memmert, 2012). Among various sports, martial arts such as karate, owning to its high pressure race condition combined with loss of concentration and memory, seems to need more goal-oriented behaviors. In a kumite, 2 karateka stand against each other and as soon as the stimulus is delivered from the opponent, the other one should provide an appropriate response. Stimulus may be a strike, mobility, or movement of the opponent's body (Pirani et al., 2014).

In such situations, the main scoring factor is decision making based on relevant information from rivals stimulus demands. Thus, karate practitioners require controlled processing and competition for dominance of relevant information as well as inhibition of irrelevant information to the stimulus (Mori, Ohtani, \& Imanaka, 2002). In this regard, accurate decisions in kumite situations is associated with WM capacity, which in turn, has great effects on karateka performances.

However, in skill acquisition literature the common assumption is that according to the learning stages of Fitts and Posner (1967), in learning process, the learner passes through different phases with different cognitive demands. Also declarative knowledge turns into procedural knowledge through this progression (Anderson, 1982). In other words, in the first stages of learning, motor skills are in a step by step fashion, resulting in using declarative knowledge. For using this knowledge, access to WM is necessary (Berry \& Broadbent, 1988).

Supposedly, concurrent with skill progression less cognitive ability is needed, also declarative knowledge turns into procedural knowledge, so less WM role is observed (Furley \& Memmert, 2010). Researchers have shown that individual differences in WM capacity predict the rate of motor learning (Seidler, Bo, \& Anguera, 2012). Also Buszard (2014) investigated the role of WM on motor learning and showed that children displayed high WM capacity advantages during verbal instructions which in turn led to better skill acquisition as well as better per- formance. Furthermore, studies with adults showed that WM capacity predicted performance in a pressured situation. Regarding the importance of WM in both providing appropriate response for the situation via controlled processing and its involvement in the first stage of skill acquisition, investigating the status and offering ways for increasing it for novice karate athletes is important.

For years, WM was conceptualized as heritable trait and resistant to extraneous influences (Campbell, Dollaghan, Needleman, \& Janosky, 1997). Afterwards attempts was made for improving cognitive acts on WM and some evidence showed that WM is flexible and can be improved by training (Tulbure \& Siberescua, 2013).

Generally, WM training can be classified into 2 groups; the first group, known as strategy training (including techniques such as the first group, known as strategy training (including techniques such as grouping items within chunks, aloud repetition, and imagination), help trainees increase their WM capacity on trained context or similar tasks (McNamara \& Scott, 2001; Morrison \& Chein, 2011; Hiroyasu, Obuchi, Tanaka, Okamura, \& Yamamoto, 2015). The second group called core training, needs continuous repetition of designed WM tasks for practicing WM performance (Klingberg et al., 2005).

In general, core trainings are computerized and many kinds of them such as CogMeg, RoboMemo, and Jungle have been created in recent years. In computerized WM training, difficulty of tasks is adjusted in an adaptive way based on participant's performance. Results of studies which used this kind of training showed performance improvements of participants on trained and or untrained WM tasks (Dunning, Holmes, \& Gathercole, 2013; Dunning \& Holmes, 2014; Delavarian, Bokharaeian, Towhidkhah, \& Gharibzadeh, 2015).

Concept of WM have received considerable attention in recent years. Today, it is a common discussion in fields such as cognitive psychology, clinical psychology, social psychology, and developmental psychology. So it is interesting that in sport psychology field this concept has received minor attention. It seems that systematic investigation of WM in sport psychology fields represents a fruitful domain of investigation of developed models validity in other fields (Furley \& Memmert, 2010). After Furley and Memmert (2010) stated the necessity of WM investigation, little studies have been done on this topic so far. They compared WM capacity of team sports athletes and paid no attention to the flexibility of WM capacity, which its importance was proven in other fields of psychology. 
In the present study, the researchers intended to clarify if WM training increases WM capacity of athletes and consequently improves their performance. Because of the importance of WM capacity in karate, the practitioners of this art were chosen for this study. It seems that their WM capacity can be associated with attention allocation process as well as selection of the appropriate response to the situation. In general, the object of the study is the investigation of effect of WM training on WM capacity and performance of novice karate practitioners of Alborz Province.

\section{Methods}

The present study is quasi-experimental with a pretestposttest and control group design. This study was performed in 2015. The population of the study was all karate practitioners of Alborz Province, Iran. Considering that karate is divided into kata and kumite, the target population was karate practitioners of kumite. Regarding the quasi-experimental nature of the study, $24 \mathrm{ka}-$ rateka were selected by convenience sampling method. The reason for this, goes back to the great dispersion of the target population. Inclusion criteria of the study were having white, yellow, or orange belts in karate with no experience of participating in official competitions and exclusion criteria were not completing WM training period. After sampling these athletes, they were randomly assigned into control and experimental groups.

Instruments used for the study were personal information questionnaire, working memory training software, digit and spatial working memory test, and performance test. Personal information questionnaire is a researchermade questionnaire and included information about sex, age, and sports background of athletes.

Working memory training software of Sina Behavioral Sciences Institute was used for WM training intervention program. This software is created by professors of Ferdowsi University in 2010, based on present theories and modeling from RoboMemo software. It is consistent with Iranian culture. Using numbers, letters, and shapes, this software presents trainings for auditory, visual, and spatial memory parts of the participants. Difficulty of each training ranges from 1 to 9 and increases automatically with the progress of participants. During training, 20 positive points is considered for each true attempt and 10 negative points for false attempt and when the points reach 100, the difficulty of training will increase for 1 level. Content validity of the software is verified by Mashhad Ferdowsi University professors and reliability of $0.89,0.90$, and 0.94 was obtained respectively for auditory, visual, and spatial memory by test-retest method.

Digit and spatial working memory test from Cambridge Brain Science collection was used to measure WM capacity of the participants. In digital WM test, participants try to memorize a list of numbers appeared in order on the screen and press on keyboard the number they see on the screen. If correct answer was provided by them, another number is added to the list in the next level, if not, a number is omitted from the list and the test would be finished after 3 wrong answers.

Spatial WM test is similar to digital WM test but numbers are replaced by colored squares. In this test, participants must memorize a series of colored squares within another $4 \times 4$ grid and point them by mouse of computer. If correct answer was provided by them, another colored square is added to the colored squares list in the next level, if not, a square is omitted from the colored squares list and the test would be finished after 3 wrong answers. Reliability index of 0.94 had been obtained by testretest method of Ghotbi Varzane et al. (Ghotbi Varzane, Zarghami, Saemi, \& Maleki, 2011) study. Furthermore, content validity of the test was confirmed by them too. In this study, the reliability index of 0.92 was obtained using the same method. In addition, in this study, participants' WM capacity was calculated by estimating their mean score on 2 tests of digital and spatial WM.

To evaluate the performance of karate practitioners in pretest stage, each novice karateka was put in one point competition condition (the practitioner who received the first points was the winner) for 10 times and the number of wins and losses were counted. To evaluate karateka performances in posttest stage, the same practitioner was put in competition condition and the number of wins and losses were counted (for selecting opponents, control group participants were used, i.e. each experimental group member competed with the same level opponent of control group). In the present study, content validity of the test was confirmed by physical education professors and reliability index of 0.90 was achieved by test-retest method.

After permission of karate board of the province, the researcher gained written informed consents of the participants as well as those of their parents. Participants could leave the intervention program whenever they wanted. Before starting the training course, all experimental and control group members took part in digit and spatial WM as well as performance tests. WM training was done for 2 months ( 25 sessions of $45 \mathrm{~min}$ ) by experimental group participants besides the regular physical exercises. WM train- 
ing was done by WM training software. WM training was done 3 sessions a week somewhere equipped with computers and in specific time periods (5:00 PM to 10:00 PM).

The experimental group was trained 6 sessions a week so that 3 sessions was karate training (even days) and 3 days for WM training (odd days). The control group participated in just karate training (on even days). Finally, at the end of training courses, participants of the 2 groups took WM test as well as performance test again (2 participants from each experimental and control group left the experiment).

Because of the study nature, both descriptive and inferential statistics were used for analyzing data. Descriptive statistics was used for description and classification of raw data. Inferential statistics was used for hypothesis testing through univariate analysis of covariance (ANCOVA). Statistical analyses was done using SPSS version 21. The significant level of $\alpha=0.05$ was considered for the study results.

\section{Results}

Age range of karate practitioners in both experimental and control groups was from 12 to 19 years (experimental group; $\mathrm{n}=10$, mean $\pm \mathrm{SD}$ age; $15 \pm 2.5 \mathrm{y}$ and control group; $\mathrm{n}=10$, mean \pm SD age; $14.7 \pm 2.3 \mathrm{y}$ ). Novice practitioners in both groups had white, yellow, or orange belts in karate Their practice was less than 6 months.

Table 1 shows mean, standard deviation of scores, WM capacity, and participants' performance of control and experimental groups in pretest and posttest stage. Also for examining normal distribution of data, KolmogorovSmirnov test was used. Results presented In Table 1 show that significant level for all variables in both groups was over 0.05 and distribution of pretest and posttest for both variables, WM, and performance was normal.

For using univariate analysis of covariance, statistical assumptions of the test was first examined and certified. According to Table 2, by removing the effects of WM capacity pretest results, a significant difference is seen between the experimental and control group regarding the posttest results $(\mathrm{P}=0.001, \mathrm{~F}=61.87)$. WM training resulted in $52 \%$ difference between experimental group and control in terms of WM capacity. Therefore, WM training has a positive effect on WM capacity of novice karate practitioners. Also, according to Table 3 , by removing the effects of performance pretest results, a significant difference is seen between the experimental and control group regarding the posttest results $(\mathrm{P}=0.001, \mathrm{~F}=15.5)$. WM training resulted in $47 \%$ difference between experimental group

Table 1. The mean and standard deviation of scores of working memory capacity and performance of groups in the pretest and posttest.

\begin{tabular}{|c|c|c|c|c|c|c|c|c|c|}
\hline \multirow{2}{*}{ Variable } & \multirow{2}{*}{ Group } & \multicolumn{4}{|c|}{ Pretest, $(n=10)$} & \multicolumn{4}{|c|}{ Posttest, $(n=10)$} \\
\hline & & $\mathbf{M}$ & SD & (K-S) Z & $\mathbf{P}$ & $\mathbf{M}$ & SD & (K-S) Z & $\mathbf{P}$ \\
\hline \multirow{2}{*}{ Working memory capacity } & Experimental & 5.2 & 0.92 & 0.91 & 0.39 & 7.3 & 0.67 & 0.86 & 0.45 \\
\hline & Control & 5.2 & 0.79 & 0.77 & 0.59 & 5.8 & 0.63 & 1.03 & 0.24 \\
\hline \multirow{2}{*}{ Performance } & Experimental & 5.1 & 0.57 & 1.17 & 0.13 & 6.2 & 1.32 & 0.51 & 0.96 \\
\hline & Control & 4.9 & 0.57 & 1.17 & 0.13 & 3.8 & 1.32 & 0.51 & 0.96 \\
\hline
\end{tabular}

Abbreviations: $\mathrm{n}=$ Number; $\mathrm{M}=\mathrm{Mean}$; $\mathrm{SD}=\mathrm{Standard}$ deviation; (K-S) Z=Kolmogorov-Smirnov Z; P=P-value. PCINICAL PSYCH LOGY

Table 2. Analysis of covariance: the dependent variable; working memory capacity posttest.

\begin{tabular}{ccccccccc}
\hline Dependent variable & Source & ss & df & MS & F & P & ETA.S & Observed power \\
\hline \multirow{4}{*}{$\begin{array}{c}\text { Working memory capacity } \\
\text { posttest }\end{array}$} & Grotest & 4.6 & 1 & 4.6 & 25.35 & $0.001^{*}$ & 0.784 & 0.984 \\
& Error & 11.25 & 1 & 11.25 & 61.87 & $0.001^{*}$ & 0.528 & 0.997 \\
& Total & 87.09 & 17 & 0.182 & & & & \\
\hline
\end{tabular}


Table 3. Analysis of covariance: the dependent variable; performance posttest.

\begin{tabular}{lllllllll}
\hline Dependent variable & Source & ss & df & MS & F & P & ETA.S & Observed power \\
\hline & Pretest & 5.4 & 1 & 5.4 & 3.6 & 0.036 & 0.173 & 0.429 \\
Performance posttest & Group & 23.5 & 1 & 23.5 & 15.5 & $0.001^{*}$ & 0.477 & 0.960 \\
& Error & 25.8 & 17 & 1.52 & & & & \\
& Total & 560 & 20 & & & &
\end{tabular}

$* \mathrm{P}<0.05$.

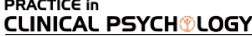

and control in terms of performance. Thus, WM training has a positive effect on performance of novice karateka.

\section{Discussion}

Based on findings of the study, a significant difference can be seen between posttest scores of WM capacity of experimental and control groups which shows the effect of WM training on increasing WM capacity of the experimental group. The present findings are consistent with findings of many other studies done with non-athlete participants in this field (Olesen, Westerberg, \& Klingberg, 2004; Dahlin, Nyberg, Backman \& Neely, 2008; Holmes et al., 2010; Schmiedek, Lovden, \& Lindenberger, 2010; Rode, Robson, Purviance, Geary, \& Mayr, 2014; Delavarian et al., 2015).

This consistency in results, despite different participants, arises from using computerized WM training. This training is designed by some kind of software which can automatically coordinate task levels and determine the difficulty of tasks based on participants' performance. This was effective in most studies that had training protocols.

Changes in mechanisms of WM capacity result from adaptive computerized training, i.e. 1) far transfer (increasing generalizability of practiced processing to the unpracticed tasks) and 2) neuroplasticity (creating nerve layers with effective and better processing arrangement) (Hovik, 2010). Neuroplasticity refers to the brain's ability to adapt and change. Research has reported increase in prefrontal and parietal activity as well as a change in biochemistry of brain after WM training (McNab et al., 2009). Also WM training is associated with the changes in dopamine receptor density and brain activity in the middle frontal and parietal cortex and basal ganglia (Olesen et al., 2004).

In addition, it is associated with the dynamic reorganization of neural substrates in the cortex (Unger- leider, Doyon, \& Karni, 2002). These findings show that systematic training can potentially induce neuronal changes in the brain. While neuroplasticity refers to the physical adaptability of cognitive structures, far transfer refers to the functional transfer of learning from one training context to another (Hovik, 2010). Within the exclusive domain of skill learning, certain types of learned skills may only have relevance to the specific task trained, while other types of learning have pervasive and enduring effects on the mind and foster generalized thinking patterns that go beyond the specific training tasks provided (Barnett \& Ceci, 2002).

The literature shows that increasing WM capacity of karateka in the intervention group can be resulted from neuroplasticity or transfer process. Most likely, karate practitioners with continuous and systematic repetition of specific cognitive processing through working memory training could improve their WM capacity by building nerve layers with better and effective arrangements or by developing generalizability of the practiced processes. Moreover, results of the study showed that WM training leads to significant improvement of performance scores of experimental group compared to control group. Considering relationship between skill acquisition and WM, results of this study are consistent with those of Anderson (1982), Berry and Broadbent (1988), Seidler, Bo and Anguera (2012), and Buszard (2014), but are in conflict with the findings about implicit learning. The relationship between skill acquisition and WM can be described by learning model of Fitts and Posner (1967).

Based on learning stages of Fitts and Posner (1967), during the learning process learner pass over different stages with different cognitive demands. During this progression, declarative knowledge turns into procedural knowledge (Anderson, 1982). Declarative knowledge is related to awareness of a task concepts (Paris, Cross, \& Lipson, 1984). As WM is responsible for the temporary storage and manipulation of information in the mind, and is the primary mechanism un- 
derpinning the conscious acquisition of motor knowledge (Buszard, 2014), acquiring declarative knowledge needs more involvement of WM. However, according to Maxwell et al. (2003), declarative knowledge processing is not a trait of all early stages of learning and that skill acquisition do not need always to advance from declarative knowledge to procedural knowledge, If so, $\mathrm{WM}$ is not involved. For example, implicit learning process does not require the involvement of WM.

Results of the present study support model of Fitts and Posner (1967) at least for karate tasks because results showed that due to WM training besides regular physical exercises, performance of novice karate practitioners in experimental group showed more improvement compared to control group ones. In fact, WM training was useful for novice practitioners, who had some cognitive problems associated to first stage of learning. And probably experimental group athletes could benefit more from WM training besides physical exercises through increasing their WM capacity during verbal instructions. And in doing so, they solve their cognitive problems which leads to their performance improvement compared to control group athletes.

Also based on principles of controlled processes (resulting from central executive of working memory), Furley and Memmert concluded that although WM capacity differences should not affect a domain of reflexive behaviors of players, it should affect behavior in postions of interference in which relying on automatic is not seasonable (Furley \& Memmert, 2010). Findings of the controlled attention theory of WM (Engle, 2002; Kane \& Engle, 2003) indicate that participants with higher WM capacity are better at acting according to a task goal instead of relying on habitual responses. Karate is a good example of a competition with high levels of timespatial limitation which needs simultaneously, high levels of quick reaction and consciousness. Also accurate decision making through concentrating on performing the task, as well as blocking irrelevant stimulus are vital factors for gaining points. Thus, karate practitioners can improve their WM capacity through WM training and these psychological advantages help them in acquiring successful performance more than ever.

Based on the results of the study, training of WM is useful for purposeful responses of karate practitioners in different kumite situations. Using such trainings is possible in the field of sport psychology, which is increasingly incorporated cognitive concepts such as attention, perception, and decision-making, which are purported to rely heavily on working memory. Because the novice participants are involved in cognitive demands and their working memory involvement is high, coaches are recommended to use WM training as a supplement to develop skill learning objectives. Also, considering that WM capacity has a critical role in decision making, attention, reaction time, as well as performance of sportspeople in sensitive moments of competition, it is recommended that professional athlete coaches use WM training periods for improving their athletes' WM capacity.

Finally, the main limitations of this study were neither controlling mental and physical maturity of athletes in both groups, nor controlling mental state of participants on the test day.

\section{Acknowledgements}

We appreciate all participants in this study and those who helped us in conducting this research.

\section{References}

Abdi, R., Chalabianloo, G., Jabari, G. (2016). Effect of mindfulness practices on executive functions of elementary school students. Practice in Clinical Psychology, 4(1), 9-16.

Anderson, J. R. (1982). Acquisition of cognitive skill. Psychological Review, 89(4), 369-406.

Baddeley, A. D., \& Hitch, G. J. (1974). Working memory. In G. H. Bower (Ed.). The psychology of learning and motivation: Advances in research and theory, (Vol. 1, pp. 47-89). New York: Academic Press.

Barnett, S. M., \& Ceci, S. J. (2002). When and where do we apply what we learn?: A taxonomy for far transfer. Psychological Bulletin, 128(4), 612-637.

Barrett, L. F., Tugade, M. M., \& Engle, R. W. (2004). Individual differences in working memory capacity and dual-process theories of the mind. Psychological Bulletin, 130(4), 553-73.

Berry, D.C., \& Broadbent, D.E. (1988). Interactive tasks and the implicit explicit distinction. British Journal of Psychology, 79(2), 251-272.

Buszard, T. (2014). Motor skill acquisition in childhood: Exploring the links between working memory, implicit learning and equipment modification $[\mathrm{PhD}$ thesis]. Australia: Victoria University.

Campbell, T., Dollaghan, C., Needleman, H., \& Janosky, J. (1997). Reducing Bias in Language AssessmentProcessingDependent Measures. Journal of Speech, Language, and Hearing Research, 40(3), 519-525.

Dahlin, E., Nyberg, L., Bäckman, L., \& Neely, A. S. (2008). Plasticity of executive functioning in young and older adults: Im- 
mediate training gains, transfer, and long-term maintenance. Psychology and Aging, 23(4), 720-30.

Delavarian, M., Bokharaeian, B., Towhidkhah, F., \& Gharibzadeh, S. (2015). Computer-based working memory training in children with mild intellectual disability. Early Child Development and Care, 185(1), 66-74.

Dunning, D. L., Holmes, J., \& Gathercole, S. E. (2013). Does working memory training lead to generalized improvements in children with low working memory? A randomized controlled trial. Developmental Science, 16(6), 915-925.

Dunning, D.L, Holmes, J. (2014). Does working memory training promote the use of strategies on untrained working memory tasks? Memory and Cognition, 42(6), 854-862.

Engle, R. W. (2002). Working memory capacity as executive attention. Current Directions in Psychological Science, 11(1), 19-23.

Fitts, P. M., and Posner, M. I. (1967). Human performance. Oxford: Brooks and Cole.

Furley, P. A., \& Memmert, D. (2010). The role of working memory in sport. International Review of Sport and Exercise Psychology, $3(2), 171-194$.

Furley, P. A., \& Memmert, D. (2012). Working memory capacity as controlled attention in tactical decision making. Journal of sport \& exercise psychology, 34(3), 322-344.

Ghotbi Varzane, A., Zarghami, M., Saemi, A., \& Maleki, F. (2012). [The effect of cognitive style on accuracy: The role of working memory (Persian)]. Journal of Development and Motor learning-Sport, 10, 61-78.

Hiroyasu, T., Obuchi, S., Tanaka, M., Okamura, T., \& Yamamoto, U. (2015). Working memory training strategies and their influence on changes in brain activity and white matter. In $\mathrm{H}$. Handa, H. Ishibuchi, Y. S. Ong \& K. C. Tan (Eds.). Proceedings of the $18^{\text {th }}$ Asia Pacific Symposium on Intelligent and Evolutionary Systems (pp. 267-278). Sydney: Springer.

Holmes, J., Gathercole, S. E., Place, M., Dunning, D. L., Hilton, K. A., \& Elliott, J. G. (2010). Working memory deficits can be overcome: Impacts of training and medication on working memory in children with ADHD. Applied Cognitive Psychology, 24(6), 827-836.

Hovik, K. T. (2010). Can PC-based training boost working memory in ADHD preadolescents on medication?: A clinical intervention study. [PhD thesis] Denmark: Oslo University.

Kane, M. J., Bleckley, M. K., Conway, A. R., \& Engle, R. W. (2001). A controlled-attention view of working-memory capacity. Journal of Experimental Psychology: General, 130(2), 169-83.

Kane, M. J., \& Engle, R. W. (2003). Working-memory capacity and the control of attention: the contributions of goal neglect, response competition, and task set to Stroop interference. Journal of Experimental Psychology: General, 132(1), 47-70.

Klingberg, T., Fernell, E., Olesen, P. J., Johnson, M., Gustafsson, P., Dahlström, K., et al. (2005). Computerized training of working memory in children with ADHD-a randomized, controlled trial. Journal of the American Academy of Child $\mathcal{E}$ Adolescent Psychiatry, 44(2), 177-186.

Maxwell, J. P., Masters, R. S., \& Eves, F. F. (2003). The role of working memory in motor learning and performance. Consciousness and Cognition, 12(3), 376-402.
McNab, F., Varrone, A., Farde, L., Jucaite, A., Bystritsky, P. Forssberg, H., et al. (2009). Changes in cortical dopamine D1 receptor binding associated with cognitive training. Science, 323(5915), 800-802.

McNamara, D. S., \& Scott, J. L. (2001). Working memory capacity and strategy use. Memory $\mathcal{E}$ Cognition, 29(1), 10-17.

Mori, S., Ohtani, Y., Imanaka, K. (2002). Reaction times and anticipatory skills of karate athletes. Human Movement Science, 21(2), 213-230.

Morrison, A. B., \& Chein, J. M. (2011). Does working memory training work? The promise and challenges of enhancing cognition by training working memory. Psychonomic Bulletin $\mathcal{E}$ Review, 18(1), 46-60.

Olesen, P. J., Westerberg, H., \& Klingberg, T. (2004). Increased prefrontal and parietal activity after training of working memory. Nature Neuroscience, 7(1), 75-79.

Paris, S. G., Cross, D. R, \& Lipson, M. Y. (1984). Informed strategies for learning: A program to improve children s reading awareness and comprehension. Journal of Educational Psychology, 76(6), 1239-1252.

Pirani, M.A., Miri, H., Hemayattalab, R., Nikookheslat, S., Haidari Moghadam, R., Khoshdast, M., et al. (2014). Comparison between balance and reaction time in Iranian elite Karate athletes. Journal of Research in Sport Rehabilitation, 1(2), 49-57.

Rode, C., Robson, R., Purviance, A., Geary, D. C., \& Mayr, U. (2014). Is working memory training effective? A study in a school setting. PloS One, 9(8), e104796.

Schmiedek, F., Lövdén, M., \& Lindenberger, U. (2010). Hundred days of cognitive training enhance broad cognitive abilities in adulthood: findings from the COGITO study. Frontiers in Aging Neuroscience, 2, 27.

Seidler, R. D., Bo, J., Anguera, J. A. (2012). Neurocognitive contributions to motor skill learning: The role of working memory. Journal of Motor Behavior, 44(6), 444-453.

Tulbure, B. T., \& Siberescu, I. (2013). Cognitive training enhances working memory capacity in healthy adults; A pilot study. Procedia-Social and Behavioral Sciences, 78, 175-179.

Ungerleider, L. G., Doyon, J., \& Karni, A. (2002). Imaging brain plasticity during motor skill learning. Neurobiology of Learning and Memory, 78(3), 553-564. 
PRACTICE in
CLINICAL PSYCH LOGY

April 2016, Volume 4, Number 2

120 